\title{
Language socialisation practices of children in multilingual Accra, Ghana
}

\author{
Yvonne Eyram Nutakor \\ Assistant Lecturer \\ Department of Applied Modern Languages and Communication \\ Ho Technical University, Ghana \\ E-mail: yenutakor@htu.edu.gh; evonnut@gmail.com
}

Nana Aba Appiah Amfo

Associate Professor

Department of Linguistics

University of Ghana, Legon, Ghana

E-mail: namfo@ug.edu.gh; nanaamfo@gmail.com

Submitted: March 17, 2017 / Accepted: January 30, 2018 / Published: June 8, 2018

\begin{abstract}
This paper examines the language socialisation experiences of children in the extensive multilingual and culturally hybrid 'compound houses' located in three suburbs of Accra. It seeks to unravel the influence socialising agents' practices and attitudes have on children's language choices and usage patterns. Blending the practice view of Community of Practice with the Ethnography of Communication model, it analyses the children's language socialisation practices within the various communities, focusing on how the socialising agents' practices shape children's language choice, use and practices. Using semi-structured interviews and participant observation, data were gathered on language choice, use and attitudes from fifty purposively selected participants who reside in six compound houses. The data reveal that the children's experiences at home are overshadowed by the language(s) used in the macro- environment. As a result, individual bilingualism does not necessarily show the presence of the parents' ethnic language. The findings further show that socialising agents' perceptions and attitudes motivate language shift and reinforcement among children.
\end{abstract}

Keywords: bi/multilingualism, language maintenance/shift, language socialisation, socialising agents

\section{Introduction}

Language, the primary symbolic medium through which cultural knowledge is communicated, negotiated, transformed 
Nutakor, Y. E. \& Amfo, N. A. A./ Legon Journal of the Humanities 29.1 (2018) and reproduced, plays a very vital role in the socialisation process across all cultures. A number of scholars, such as Ghimenton et al. (2013), Ildikó (2010), Delgado (2009), Garrett and BaquedanoLópez (2002) and Gleason (1988), assert that children acquire and develop language only when the human infants are raised in an interactive social context, which has the required linguistic inputs the children need. In the past decades, language socialisation studies by Suzuki (1999), Ochs (1988), Schieffelin and Ochs (1986a, 1986b), Gleason and Weintraub (1978) have broadened our understanding of the numerous ways through which the development of language and socio-cultural competences in children are facilitated simultaneously for them to become competent members of their speech communities.

Although Ghana's national capital, Accra, is an ethnically $\mathrm{Ga}^{1}$ city, the increased scope of rural-urban migration, over the past decades, has resulted in the creation of a highly multilingual community with (im)migrants in the metropolis. According to the 2010 Census report, 2,793,679 million people are (im)migrants in Accra (Ghana Statistical Service, 2012). These people have migrated with various ethnic languages other than $\mathrm{Ga}$, the ethnic language of the capital. The existence and interaction of these languages have compelled some residents to learn some other language(s) in addition to their own ethnic ones. However, a number of residents still use their ethnic languages solely in various communicative contexts at home.

'Compound houses'2 in certain suburbs of Accra, the capital of Ghana, such as Accra Newtown, Madina and Nima, are places explicitly characterised with multiple language contact situations at both individual and community levels. As a result, most children found in these houses experience social settings which reflect either language influence or interference that leads to language reinforcement, shift, loss or maintenance. Makihara (2013, p.1), in explaining some likely causes of language change and shift in

$1 \mathrm{Ga}$ is used to refer to the natives of Accra as well as the indigenous language spoken by these people.

2 Compound houses are structures that accommodate two or more households within a single com pound. They depict the Ghanaian concept of communal living.

Legon Journal of the Humanities 29.1 (2018)

Page | 163 
Nutakor, Y. E. \& Amfo, N. A. A./ Language socialisation practices of children

Rapa Nui on Easter Island of Chile, stresses that 'language and community change through the friction of daily interaction.'

Taking the above into consideration, the present paper examines the language socialisation experiences of children in various social interactions within these multilingual and multicultural compound houses. The study focuses on how interrelated socialising agents' language choices and usage are to children's language socialisation practices and demonstrates how the attitudes of various agents influence children's language learning and usage patterns. Additionally, it discusses the notion of language vitality, bi/multilingualism, ideology and identity and their correlation with language maintenance, reinforcement and/ or shift in the communities. To understand the communicative activities, linguistic practices and language socialisation of the children, some related studies on the subject are first evaluated. A discussion of the theoretical framework underpinning the study then follows. The subsequent sections deal with the methods used in gathering data for the study, the presentation of the findings of the study and the discussion of the language socialisation practices in the multilingual communities chosen for the study. The final section is the conclusion.

\section{Related studies}

Children's language acquisition and the development of their socio-cultural competence have been the focus of many language socialisation studies. A number of scholars, for example Huang (2011), Minks (2010), Gleason and Nan (1998) and Schieffelin and Ochs (1986a, 1986b), who have studied these phenomena attach great importance to the correlation between socio-cultural and pragmatic analyses of the language socialisation processes of children and language learners in general. This section reviews some previous literature on trends in children's language development, language socialisation, multilingualism, language maintenance and/or shift. 


\section{Language development and language socialisation}

Ochs and Schieffelin (1986a, 1986b) explain language socialisation as an interaction between a child and a caregiver with the aid of language. They argue that for a child to function effectively within a speech community, importance should be placed on the simultaneous development of language and cultural competencies. This, they believe, depends on the expertise of the individual caregivers to positively affect the child to acquire the structures of a language as well as its functions and social distribution across defined situations. They envisage the language socialisation as a process which encompasses acquiring a language and knowledge of its function and social distribution.

In a similar vein, Gleason (1988) emphasises how language is acquired interactively through dialogue and social interaction with others. She reveals that when parents engage their children in interpersonal and social activities, explicit and subtle information about the language is transmitted to the children. Her findings suggest that language socialisation includes a blend of language exposure, acquisition, development and cultural transmission which occur either explicitly or implicitly and, in most cases, both ways. Therefore, a child's language choice and use reflect not only competency but, also, the positive or negative influence of parents.

On the other hand, Cook (1999) postulates that the participation structure in Japanese classroom interaction helps socialise Japanese children to the culturally important skill of attentive listening. This, she believes, shapes children's public speaking abilities to express their views subjectively. She notes that these school children are able to develop cognitive and social skills simultaneously. In all these cases, the communicative events were based on the use of the same language variety within the same context of caregiving. Therefore, this study will discuss the language socialisation practices that encompass how children learn language(s) within the same complex communicative context but from multiple agents and varied events. 
Nutakor, Y. E. \& Amfo, N. A. A./ Language socialisation practices of children

\section{Language choice and multilingualism}

Baquedano-Lopez and Kattan (2007) explain multilingualism to involve the acquisition and use of two or more languages in contexts where the forms make meaning. In their view, multilingualism is a trait of the individual that depends on the linguistic situation of the community. With regard to the analysis of how children are socialised to use multiple forms of language within a multilingual community, Howard (2003) demonstrates how children in Northern Thailand use the Standard Thai and Kam Muang simultaneously during interaction at school. He asserts that though Standard Thai (ST) is the official school language, the children are socialised into language hybridity in the classroom. According to him, to be regarded as using language appropriately for the classroom, kindergarten children are instructed to speak politely in their native language, Kam Muang, but to use honorific particles of Standard Thai. This communicative competence, Howard stresses, reflects the community's positive perceptions about the assigned roles for the languages. In effect, children's code-mixing behaviour in the classroom is considered to be their readiness to learn the linguistic structures of Standard Thai - vocabulary, grammar and pronunciation. In his view, the school environment exhibits a positive attitude to the phenomenon which leads to bi/multilingualism, hence the language and socio-cultural modes of teaching and care giving are rooted in the cultural values of the Lanna people of Northern Thailand.

Guerini (2007), on multilingualism and language attitude in Ghana, notes that English is assigned higher prestige and is perceived as the only language worth investing in (both financially and cognitively) from childhood, at the expense of local languages. She believes that most local languages have been learnt in a spontaneous way from home, school and the multilingual environment; hence the linguistic repertoire of non-Akan speakers is more complex with three or four languages than the native $\mathrm{Akan}^{3}$ speakers. She adds that the minority language speakers are motivated to develop a good command of dominating languages in addition to their native language because of the real and perceived socio-economic value,

3 Akan is the dominant Ghanaian language in the country. Almost half of the population speak it as their L1 (GSS 2012), and many others use it as a lingua franca.

Legon Journal of the Humanities 29.1 (2018)

Page | 166 
increased access to education and job opportunities for a better living that these dominant languages offer.

For her part, Minks (2010) notes that language use in the community of Corn Island (off the Caribbean coast of Nicaragua) demonstrates how children are socialised into multilingual abilities. Presenting historical, ideological and structural perspectives on the multilingual use of language, she observes that the language socialisation on the Island is a communal responsibility of parents, older siblings, other members of the family and the community. These people help the younger children acquire linguistic and socio-cultural competence based on the agents' competence and perception about which language would best serve the interest of the children in the future. Minks adds that many parents with an additive view of language maintain contexts for their children to learn more than one language. A few parents who have a subtractive view of language explicitly shift repertoires without sometimes even realising the shift. She observes that the use of English and Spanish words and phrases in caregivers' register is an index of a positive attitude to multilingualism in the language socialisation process on Corn Island. She concludes that language is a pool of communicative resources that is used to socialise children into a heterogeneity of expressions within and across the languages present on the Island, which are Spanish, Miskitu and Creole English.

Luykx's (2003) study supports the idea of an explicit positive attitude of socialising agents towards bi/multilingualism. She examines language socialisation in terms of gender and avers that although the young children (boys and girls) are exposed to both Spanish and Aymara by their bilingual parents, the children use Aymara because it is the dominant language within the community. She reveals that the children acquire the sound system, morphology and grammatical rules of their mother tongue and speech styles suitable to their gender. The children, Luykx further notes, develop the good communicative strategy of showing politeness in a bilingual context and competence through observation and imitation of their parents, grandparents, siblings and other neighbours during interaction within the speech community. She concludes 
Nutakor, Y. E. \& Amfo, N. A. A./ Language socialisation practices of children that mixing and switching between two languages are explicit in this speech community because most children grew up with at least a bilingual parent who demonstrates such a practice. On the basis of these works, the present study probes the occurrence of bilingualism/multilingualism in children's language socialisation processes within the selected multilingual houses in Accra.

\section{Language maintenance and/or shift}

Language contact has been understood as a situation within a speech community in which two or more languages circulate and struggle for linguistic space (Batibo, 2005; Garrett, 2004). The situation occurs as a result of factors such as migration, urbanisation and colonisation, as groups from different cultures and linguistic backgrounds come into contact. The possible result of this situation translates into bilingualism, multilingualism, language maintenance, loss and/or shift by speakers. Language maintenance and/or shift are explained as language contact situations in which a speech community may decide to keep their respective languages in all domains, agree to take and use a new language in all domains or use the newly acquired language in specified domains (Batibo, 2005). Thus, language maintenance and/or shift are viewed as a social process because both evolve around identity and ideology.

In a language socialisation study of the role of language ideology in the maintenance of Spanish, Pease-Alvarez (2003) probes the role of parent's convictions, experience, cultural practices and social positioning on children's Spanish language socialisation among 63 young people of Mexican descent and their family members in Eastside California. She finds that parents have positive thoughts about English-Spanish bilingualism and native language maintenance. Mothers, she argues, claim sole responsibility for the acquisition and maintenance of the Spanish language among the families observed. However, the findings reveal that the competitive changing linguistic values assigned to some languages encourage some parents to consciously use only English language with their children as a means of preparing them for life outside their homes. 
Nutakor, Y. E. \& Amfo, N. A. A./ Legon Journal of the Humanities 29.1 (2018)

Sarkar and Park's (2007) case study on parents' attitude towards Korean language maintenance in Montreal reveals that the Korean immigrant children's ability to maintain the Korean language is largely influenced by the positive principles, mindset and attitude of their parents. They add that the children's high proficiency in the Korean language is strongly connected to the development of their cultural identity in the speech community.

In Ghana, Bibiebome's study (2010), on the loss of popularity of the Ga language in most suburbs of Accra, investigates language shift and maintenance in the city. He argues that Accra has now become a vibrant multilingual society where Ga, the ethnic language, competes with other Ghanaian languages in various linguistic domains. According to Bibiebome, the interference of other languages in the use of Ga has resulted in a possible shift from its previously dominant use to other languages such as Akan, English, Ewe and Hausa, in many linguistic domains including the home, church, market and school. He notes that majority of settlers in Accra do not lose their native languages. Rather, they reinforce them with Akan, English or another dominant language which may not be $\mathrm{Ga}$. In his conclusion, he asserts that most residents in Accra have developed the urge of using Akan and English in most communicative domains due to the dominance and prestige associated with these languages. This reveals a language shift process in Accra.

In addition to these major studies, Tsikpo (2010) investigates the linguistic behaviour of children of Ewe origin in Accra. He argues that the Ewe language, a minority language within the study area, is put to restricted use. Using Auberger's language shift and maintenance model (Batibo, 2005), Tsikpo shows that some parents with Ewe ethnic background have negative attitudes to their mother tongue thus they consciously socialise their children to the use of various Ghanaian languages other than Ewe, their native language. This practice, he explains, seems to result in an implicit functional role assignment to languages, according to the dominance of the code in the community or a language shift phenomenon which is influenced by the parents' and/or guardians' educational level. He 
Nutakor, Y. E. \& Amfo, N. A. A./ Language socialisation practices of children

further observes that parents' shift to English and Akan as socialising codes will enable the children to adjust to communicative events in the speech community they find themselves.

These studies mainly focused on dyadic language socialisation of children (soothing, play, etc.) within limited groups - siblings, caregivers, parents or teachers and revealed a trend in the linguistic and communicative practices of the children studied. While the above studies certainly provide various useful models for the present inquiry to demonstrate how socialisation practices, structure of participation and attitudes about language(s) affect children's language use, it is observed that language socialisation practices of children within Ghanaian multilingual contexts has received little or no attention from the academy. A critical look at these children's language use pattern points out that the children acquire linguistic resources from people of different linguistic and socio-cultural backgrounds. This is done through observation, imitation and role play. Hence, the present study explores the extent to which the varying compositions of the communicative situations contribute to the language socialisation of Ghanaian children living in selected multilingual communities. Further, it will provide an indication of whether children of the current generation are being assisted to reinforce, shift or maintain their ethnic languages.

\section{Theoretical framework}

The Ethnography of Communication approach is based on the notion that communicative activities are blends of culture and patterns of language usage which aid speakers to learn and attain communicative competence to communicate effectively within a speech community (Saville-Troike, 2003; Hymes, 1962). The speech community is viewed as 'groups that shared values and attitudes about language use, varieties and practices' (Morgan, 2014, p.1). This framework proposes three main dimensions for the analysis of the patterns of the communicative activities as: communicative situation, communicative event and communicative act. These dimensions are explained as follows: 
The communicative situation of a speech is the context within which communication occurs although there may be great diversity in the kinds of interaction which occur there. The communicative event is the basic unit for descriptive purpose and the communicative act is generally coterminous with a single interactional function of a statement, request or command that may be either verbal or non-verbal. (Saville-Troike, 2003, pp. 23-24)

According to Saville-Troike (2003), the status, composition, event and act are crucial units which combine to account for how language and linguistic forms and patterns are selected and used in interactions within a speech community. By adopting both communicative situation and communicative event models, we try to show that the households, compounds, environs and playgrounds in Accra New Town, Madina and Nima are not only encouraging fields for language socialisation, but are also avenues for the development of linguistic practices. We focus on how socialising agents' attitudes shape children's language choice and use in various communicative domains.

Also of particular importance to this paper is the practice view of Community of Practice, which is concerned with how the children and their socialising agents participate in various social activities within the speech community as practice, rather than the children being trained to achieve competence (Wenger, 1998). We use the practice view to discuss the various instances of interactions within which the children demonstrate some of the linguistic practices. The blend of the two models creates an essential opportunity for us to explore the various means for the development and use of the acquired linguistic practices by the children.

\section{Methods}

The study is sited within three suburbs of Accra namely: Accra Newtown, Madina and Nima. These three suburbs are chosen because they are fairly representative of the multilingual status of Accra. In addition, they provide an avenue for close social network 
ties and neighbourhood interconnections. Two of the three suburbs (i.e. Madina and Nima) have Zongo ${ }^{4}$ communities with brisk socioeconomic conditions that reflect environments in which several languages are in contact situation every day. Socially, all the three areas are densely populated with people from all walks of life and many residing in compound houses where families share basic facilities. In terms of infrastructure, social amenities and education, Accra New Town (formerly known as Lagos Town) and Madina generally have a number of offices, stores and relatively wellresourced schools. The common languages for communication here are Akan, Ewe, Ga and English, with other languages such as Dangme and Hausa in the background. Madina is more vibrant commercially than Accra New Town. Nima is a typical Zongo community with congested settlements. The area is noted for brisk commercial and social activities (parties, marriages, etc.). Hausa is the lingua franca of the Nima community.

Fifty participants including thirty children and twenty adults were involved in the study. The adults were aged 25 and above, while the children were between 5 to 10 years old. The children, who were the focus of the study live in six purposively sampled compound houses, where they interact with multiple members of the compound houses and others in the larger environs on a daily basis. In all, ten children were selected from each suburb. Audio and video tape recordings of routine interactions of the children and adults in varied communicative situations and events were used to gather data on participants' language socialisation practices. Data were collected from July to December, 2014. Participants' bio-data, information on children's experience with language use in the communicative contexts, as well as the adults' attitude to language choice and use were extracted through semi-structured interviews with the help of an interpreter in all the communities, when needed. The interviews with all adult participants lasted for approximately thirty minutes each. Additionally, participant observation was undertaken to establish the language practices and

4 Zongos are slum settlements within African cities and big towns. The occupants of these settlements are predominantly but not exclusively Muslim immigrants from Northern Ghana. 
linguistic behaviours of the children during various communicative events (play, conversation, etc.). During the observation, 60 minutes was spent with the children each time they were observed, as they interacted with one another and with adults in the various situations.

\section{Findings and discussion}

\section{Compound houses as speech community and communicative situation}

The selected compound houses in Accra New Town, Madina and Nima as speech communities have members (children and adults) who live communally and have shared values and facilities. Although members may have different cultural and linguistic exposures, they interact regularly, using their ethnic language(s), negotiating or adopting a common language in specific contexts. With regard to complex communicative environments, three different groups were identified from the data: households/homes (immediate family), neighbourhoods (adults, teenagers, peers) and the external environs. Within the households are various codes such as: Akan, Ewe, Hausa, Gurene, Chamba, Larteh, Gonja, Dangme, Ga, English, and Kotokoli. This information suggests to us that the communicative situation is a multilingual context where each language competes for usage. We observe that one or multiple socialising agents consciously or unconsciously socialise the children to one or more of these languages through events such as play, conversation and dialogue. Sometimes, the codes are not necessarily the parents' ethnic language(s). Samples of languages that families use with their children are demonstrated in Table 1. 
Nutakor, Y. E. \& Amfo, N. A. A./ Language socialisation practices of children

Table 1: Linguistic repertoire of sampled families in study areas

\begin{tabular}{|c|c|c|c|c|c|c|c|c|c|}
\hline Suburbs & \multicolumn{3}{|c|}{ Accra Newtown } & \multicolumn{3}{|c|}{ Nima } & \multicolumn{3}{|c|}{ Madina } \\
\hline Households & $\mathbf{A}$ & B & C & D & $\mathbf{E}$ & F & G & H & I \\
\hline $\begin{array}{l}\text { Languages } \\
\text { spoken at } \\
\text { home with } \\
\text { children }\end{array}$ & $\begin{array}{l}\text { Akan } \\
\text { English }\end{array}$ & $\begin{array}{l}\text { Hausa } \\
\text { Akan } \\
\text { Ga }\end{array}$ & $\begin{array}{l}\text { Ewe } \\
\text { Akan }\end{array}$ & English & $\begin{array}{l}\text { English } \\
\text { Akan } \\
\text { Ewe }\end{array}$ & $\begin{array}{l}\text { Gonja } \\
\text { Chamba } \\
\text { Dagbani }\end{array}$ & Gurene & $\begin{array}{l}\text { English } \\
\text { Larteh } \\
\text { Akan }\end{array}$ & $\begin{array}{l}\text { Dangme } \\
\text { Ewe } \\
\mathrm{Ga}\end{array}$ \\
\hline $\begin{array}{l}\text { Ethnic } \\
\text { Language/L1 }\end{array}$ & Akan & $\begin{array}{l}\text { Chamba- } \\
\text { Kotokoli }\end{array}$ & Ewe & Akan & $\begin{array}{l}\text { Ewe } \\
\text { Akan }\end{array}$ & $\begin{array}{l}\text { Gonja } \\
\text { Chamba }\end{array}$ & Gurene & Larteh & Dangme \\
\hline
\end{tabular}

Source: Field data

Again, owing to the different languages available within the homes, it appears that the socialising agents select a language/code which allows for the maximum participation by all within a specified domain.

Another feature worth noting about the communities is the ethnic composition of the various families. Within Accra New Town, Madina and Nima, twelve families with the same ethnic background and eighteen families of mixed ethnic background create an immediate communicative situation for the children's language socialisation and an opportunity for negotiation and choice in language use. Of these thirty families, nine families use only Ghanaian languages (Akan, Ewe, Ga, Gonja, etc.) in interacting with the children at home in all domains such as giving instructions, assisting in children's homework and reprimanding. An example of how socialising agents' language choice affects a child's language choice is when Mr. A, an Akuapem (Akan sub-group), on all the visits, used the Akuapem dialect to give compliments to his 7-year old child after he had finished supervising the child's homework. By so doing, the child learns and uses Akan at home. This results in the child's frequent use of Akan in interacting with other interlocutors. For example, Mr. A congratulates his child saying"

5 Abbreviations used in this paper are as follows: 1 - First person, 2 - Second person, 3 - Third person, DEMONS - Demonstrative pronoun, IMP - imperfect, MP- motional prefix, OBJ Object, PART - Particle, PL - Plural, PREP - Preposition, PROG - Progressive, SG - Singular. 
Nutakor, Y. E. \& Amfo, N. A. A./ Legon Journal of the Humanities 29.1 (2018)

$\begin{array}{lll}\text { 1. Mo! wo- } a-y \varepsilon & \text { ade! } \\ \text { Good! 2SG-PERF-do thing } \\ \text { 'Good! You have done well.' }\end{array}$

Mr. A praises his child in Akan for accomplishing his work neatly. This practice is often seen in the child's speech as there seems to be a reciprocal use of Akan with parents. On the other hand, twenty-one families use Ghanaian and non-Ghanaian languages simultaneously or only a non-Ghanaian language, especially English, in varied interactive domains. For instance: A Dangme mother uses Akan to call her child to the dining table. Below is the interaction:
2. Mum: Emmanuel! Emma! be-di banku. Emmanuel! Emma! MP-eat banku
'Emmanuel! Emma! come and eat banku.' Emmanuel: Yoo, Maa.
Ok, Mama
'Ok, Mama.'

In (2), Emmanuel and his mother interact in Akan, when she is inviting the boy to eat but she uses English to reprimand him, as seen in (3) below:

3. Mother: Emma, stop what you are doing! Shame! Emmanuel: (stopped what he was doing) Ok

The mixed ethnic background families consist of parents from culturally and linguistically diverse groups with varied ethnic languages. During interactions, some of these families use a third language or accommodate to the children's language. Accommodation arises in contexts where a speaker has to intentionally use a language that the child is comfortable with. In instances where one of the parents has acculturated to the partner's language, that language is used as the language of the home. For instance, in one of the homes, the father's ethnic language is Chamba, while the mother's is Ga. Since the father is fluent in Ga as well, Ga is used as the language of the home, as seen in (4). 
Nutakor, Y. E. \& Amfo, N. A. A./ Language socialisation practices of children

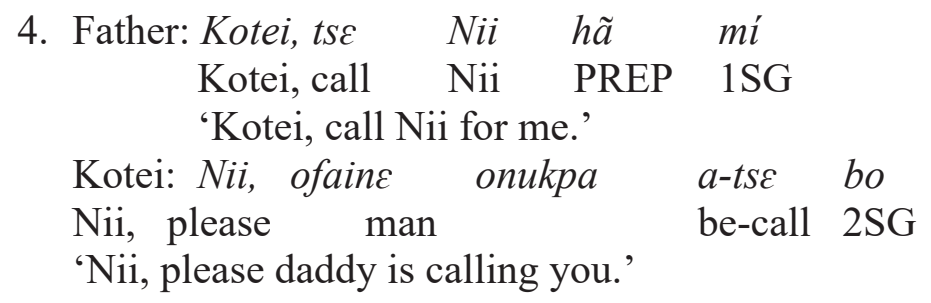

More interesting than this is when the families adopt a third language other than the parents' ethnic language(s) to socialise the children. For instance, in one household with an Akan mother and an Ewe father, they use a third language, English, for communication among themselves and with their children in and outside the home. This is in consonance with Dako and Quarcoo's (2017, p.24) finding that English is gradually assuming L1 status in Ghana as more parents choose to speak it at home. An example of such an interaction is provided in (5).

5. Mother: Maame, come and do something for me. Maame: I don't want to come. Aseda is eating all my food so I don't want to leave the food with her.

Mother: Learn to share.

Another feature of the language practices observed is that even in households where parents have a common language, they sometimes use the dominant language of the community (which is different from their own common language) to socialise the child(ren). Some of the families in Nima use Hausa while those in Accra Newtown and Madina mostly use Akan and/or English, depending on the families' choice.

We realise that in some homes (families), the eldest children have some languages in their repertoire which the younger ones do not have. For instance, the eldest children of two families visited in Nima speak Gurene or Chamba with their grandmothers, Hausa and Akan with their parents, and Hausa or Akan or English with their siblings. The younger children within these same families speak only Hausa with their grandmothers, and Hausa and Akan 
with their parents. Interestingly, all the four single parent families socialise their children to their ethnic language whereas the remaining households use various languages depending on their preferred language choice and the domain of interaction.

A quality worth noting is how neighbours in the compounds and the multiethnic and multilingual environs create the linguistic opportunity where some children, if not all, learn and use a variety of language(s) outside their immediate family settings. The data reveal that majority of the children are socialised to use the dominant language(s) of the suburbs, irrespective of the ethnic language(s) of their parents, or they use English, as a way of assisting them to effectively communicate within and beyond the communities.

We observe that to enable children participate in communicative events, from time to time, some socialising agents (neighbours, peers, siblings, etc.) accommodate or adjust to the children's language choice. For instance, example (6) below illustrates how a hospital attendant who is a non-native Akan speaker adjusted to Joe's (a 6-year old boy) language choice. During the interaction, the hospital attendant quickly changed from using English to Akan, when she realised that Joe was not answering the questions she had asked him. This scene occurred in front of Joe's house in Madina.
6. Joe:
Obroni!
Obroni!
Obroni!
'White person!
White person!
White person!'
Hosp. Attendant: Biibiini!
Biibiini!
Biibiini!
Black person! Black person! Black person!'
What's your name? Do you like me? Give me five. ${ }^{6}$
Joe: Mama to shoe wei ma me.
Mother buy shoe DEMONS give 1SG.OBJ
'Mother, buy this shoe for me.'
Mother: His name is Joe.

6 A high five 
Nutakor, Y. E. \& Amfo, N. A. A./ Language socialisation practices of children Hosp. Attendant: Joe, Wo-pe me anaa wo-pe panee? 2SG-like 1SG.OBJ or 2SG-like needle $\begin{array}{lll}M a & \text { me } & \text { five! } \\ \text { Give } & \text { 1SG.OBJ five }\end{array}$

'Do you like me or do you like the needle? Give me five.'

As part of the accommodation process, the hospital attendant repeated the question in Akan to create an enabling context for the child, where the latter could then use the shared language to answer the former's question. The child chose to ignore her and speak Akan with his mother.

The hospital attendant's Akan utterance to Joe is pragmatically inappropriate, which betrays her non-native speaker status. $^{7}$ In spite of her inadequacies, she still willingly adjusts codes in order to attempt to make meaningful conversation with Joe. As seen in Example 6 above, the communicative event involved multiple participants who have various languages in their repertoire. It, also, illustrates how Joe interrupts the conversation with a request to his mother using Akan, but a swift answer by his mother rescues the situation for the conversation to continue.

Further, we demonstrate that the structure of participation during interactions is multi-party, rather than dyadic, since the communicative act involves more than two interlocutors. Not all the participants are necessarily caregivers of the child(ren) as espoused by Ochs and Schieffelin (1986a, 1986b). Thus, the children are routinely exposed by many people to the opportunity for learning diverse languages. This situation orients the children to be multilingual so they can easily be integrated into the larger communities of interlocutors. In view of this, we argue that the children's language socialisation process in the compound houses creates a communal environment for practising and building rapport rather than individualistic acts of imitating adults (such as parents and caregivers).

7 The correct expression should be wope m'ascm anaa wope panee? 'Do you like me or do you like the needle?'

Wope me? translates correctly as 'Would you like me as a girlfriend?' 


\section{Multiplicity of languages}

There are thirteen languages in the six compound houses visited, thereby making them multilingual contexts which require, to an extent, the children learning new utilitarian codes. Eleven of these languages are indigenous Ghanaian languages - Akan ${ }^{8}$, Ewe ${ }^{9}$, Larteh, Gurene, Ga, Dangme, Kotokoli, Chamba, Gonja, Dagbani and Wala, and two are non-indigenous languages - Hausa $^{10}$ and English. The eleven languages are spoken as first languages or ethnic languages of the various adult participants. The multidirectional nature of the communicative events in these compound houses demands children's knowledge and use of different languages depending on the interlocutor's competence, choice and topic. English, the official language of Ghana, is used at home and within its external environment (beyond the home). It is mostly used in schools. As a result, in the compound houses and their environs, the children learn languages and construct identities from at least one of the socialising agents, if not all. In one household, children actively practise alternating between multiple languages in their interaction. Ewe is used with only one member of the family (grandmother) while Akan and English are used with other members, parents and siblings.

We realise that few mothers (17\% of our sample) use predominantly English, while majority $(83 \%)$ of them use Ghanaian languages with the children. On the other hand, $27 \%$ of the fathers use English while $63 \%$ of them use the various Ghanaian languages in socialising children at home. Significantly, within the communities, parents make use of more than one language during a single conversational interaction with children. This language use pattern was captured at home during conversation, when assisting children with their assignments, pampering, scolding children and during play time. In the extract presented in (7) below, a mother and a father use two languages (Akan and English) as they try to assist

\footnotetext{
$8 \quad$ Akuapem, Asante and Fante were the varieties identified within the compound houses.

9 Evedomegbe, Tongu, Anlo and Gengbe were the varieties of Ewe used within the compound houses.

10 Hausa is a Chadic language. Even though it is not indigenous to Ghana, there are Ghanaians who speak it as their L1.
} 
their eight-year old child with her homework.

7. Child: Maa! Maa! Maa!

Mother: Yeeeeeessss!

Father: Why is she making noise like that?

Child: They have given me home work but I don't understand.

Father: You don't understand doesn't mean you should make noise. Let me see.

Child: They say box plus box is equal to four.

Mother: Eiiii!box plus box is equal to four?

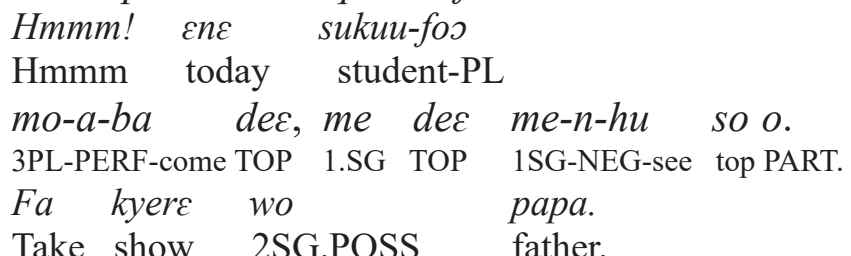

Take show 2SG.POSS father.

'Students of today, as for me, I don't understand it.

Show it to your father.'

Father: Box plus box is equal to four, it means you need to add two things to get four.

Wo-de two be-hye boxbaako mu na wo-a-kan 2SG-take two FUT-put box one in CONJ 2SG-CONS-count two bio a-hye another box mu two again CONS-put another box in

'You first count two and put it into one box and count another two and put it into another box.'

Is that okay?

Child: Ok Dad, one, two, three, four ...

Generally, we observe that fathers use more English in their conversation with their children than mothers do. For example, in a household at Madina, Mr. J uses English with his children as seen in (8). 
Nutakor, Y. E. \& Amfo, N. A. A./ Legon Journal of the Humanities 29.1 (2018)

8. Mr. J: Eugene! Why have you put that sound in the speaker? It is so loud.

Eugene: Ah Dad! I was playing music. It is not intentional.

Mr. J: Reduce it. It makes a lot of noise.

Eugene: (presses the button to decrease the sound). Is it ok now?

In all these contexts and events, we note that participants produce shared language skills which are reflective of the interactive status of the community.

\section{Language vitality}

Our data reveal that in the multiplicity of languages in the three suburbs, there are only five languages which are in active use in all domains where the children interact and practice - home, school, playground, game centres and the neighbourhood. These are Akan, English, Ewe, Ga and Hausa. The use of English, Akan and Hausa appears widespread in all the communicative domains because in the communities, as shown in the data, they are used as lingua franca by speakers who, otherwise, do not have a common medium of communication. Also, they are the most commonly used languages by socialising agents to establish and maintain interactions. Their use is reflected in children's interaction at play, school, game centres, etc.

Interacting with participants during the interview and participant observation, we note that Akan and Hausa are widespread not only because they have a lot of speakers but also because of their use as the main languages of trade within the communities. English, on the other hand, is considered the most prestigious language because of its official and educational value in the country. Many participants stressed that English is the language of power and security. The adult participants expressed positive views regarding the future implications for their children's ability to speak English. Thus, they hold the view that there is the need for one to invest in English acquisition in order to secure a brighter future for one's children. Though Ewe and Ga are considered to be less powerful than the other languages mentioned earlier, some 
children use them especially when they want to exclude others from the conversation. This is illustrated in (9).

Background: Six children were watching a movie on a desktop computer when, suddenly, the issue of who would operate the computer came up. Among them were two children who could speak Ewe and Ga in addition to English and Akan. As the discussion unfolded, the duo used Ewe instead of English or Akan. This is how their conversation went:

9. Akos: We have to watch both parts one and two of this movie. Then we can summarise it for Aunty Kate.

Joe: Mamle will type it so that we can have an organised work.

Amet: She doesn't know where the characters are hiding. Hahahahaha!

Mamle: (laughed) Amet! Agbe mele asi-wo o. Amet life NEG.have hand-POSS NEG 'Amet! You are bad.'

Amet: Nyatefe ko meto.

Truth FOC 1SG.tell

'I just told the truth.'

Mamle: Ne mili koa ke midod’ na miadokuiwo.....

If 2PL.be.there FOC then 2PL.work giving 2PL.POSS.selves

'You always want us to be engaged.'

Once the two started using Ewe, the rest of the children felt excluded from the discussion. The other participants are, however, not motivated to learn Ewe since it is a small in-group language. This confirms Guerini's (2007) findings that speakers of nondominant Ghanaian languages are multilingual with more than three languages in their linguistic repertoire.

We, also, notice that the use of English is more common among the younger children (6 years and below) as compared to the older ones of 8 years and above. This may be attributed to the 
increased use of English in pre-school and the growing trend of parents' use of English as medium of communication with children at home. Another reason is that some parents, peers and other adults expose the children to English language-mediated interactions at home and within the community as their first language or second language in some cases. This trend is supported by Ayoola and Soneye's (2016) study of Yoruba-English bilingual children in Nigeria. An instance of this practice is given in examples 4 and 5 cited earlier. The practice, also, confirms Bibiebome's (2010) study that Ga is losing its popularity in Accra and Tsikpo's (2010) study that parents socialise their children to languages that are different from their ethnic languages.

\section{Linguistic practices}

In these diversified linguistic environments, parents are aware of the existence of individual and community bilingualism/multilingualism. This is because language learning and communicative practices in the homes contrast sharply with what transpires in the compounds and their environs. Words from different languages are used during communicative activities, characteristic of code-mixing. There are also practices that lead to language shift and/or maintenance in the communities. Hence, the parents explicitly and/or implicitly socialise the children to these practices.

\section{Code-mixing}

The use of code-mixing is prevalent among both adults and children in the home, at play, at school and in the larger community. Code-mixing refers to 'any instance of interchanging usage of two or more languages within the same conversation or discourse by the same multilingual speaker' (Wolff, 2000, p.5). In this sense, code-mixing may take the form of transferring words and phrases from one language into another language during interactive events. In the compound houses in all the suburbs, code-mixing is bidirectional. The adult participants code-mix when interacting with the children, while the children code-mix among themselves and in their interaction with adults. Many parents confirmed that 
they code-mix in interactions with the children.

The code-mixing pattern found in children's speech within the three communities is discourse-related insertion. Participants insert a lexical item from one language while predominantly using another language during most of their interactions. They use either two Ghanaian languages or a Ghanaian (for example, Akan, Ga, Dangme or Ewe, etc.) and a non-Ghanaian language (for example, Hausa or English), depending on the codes the speaker has in his or her repertoire. The dialogue between Akosua and Doris, in (10), is an instance of code-mixing among two young girls in one of the suburbs. The example illustrates participants' discourse-related insertion during communicative events. In the dialogue, Akosua (A) and Doris (D) are considering the food they should eat for lunch that day.

$$
\begin{array}{rlll}
\text { 10.A: } \varepsilon n \varepsilon, & \text { mo-m-ma } & \text { yen-ni } & \text { jollof. }{ }^{11} \\
\text { Today } & \text { 3PL-IMP-let } & \text { 3PL-eat } & \text { jollof }
\end{array}
$$

'Let us eat jollof today.'

D: Ooh! Ah!, Wo-pe jollof-sem too much.

Ooh! Ah!, 2PL-like jollof-matter

'You like talking about jollof issues too much.'

In (10), D intra-sententially mixes Akan with English knowing very well that A will understand what she means. D's use of the English phrase 'too much' in this exchange signifies her ability to use both codes. The intra-sentential mix is common within all the communicative events because it involves the incorporation of single words or phrases (noun, verb, adjective, etc.). The data seem to suggest that the use of code-mixing within the houses and their external environs is because parents want the children to easily understand structures in the various languages. Again, it is seen as an indicator of the research participants' display of their

11 A West African dish prepared using rice, vegetable oil, tomato sauce, pepper and meat or fish. 
multilingual competencies.

Another instance of discourse-related insertion was observed during a misunderstanding between some boys and girls who had returned from school in Accra Newtown. A woman, who was observing the scene, tried to settle the matter. She then asked what the matter was, in English. One of the younger girls was proving stubborn, so the woman retorted:

11. Woman: What are you going there for?

Girl: I am going to kyekyere this thing.

tie

Woman: Wo-re-ko

kyekyere

den?

2SG-PROG-go tie what?

'What are you going to tie?'

Girl: This thing.

There is the insertion of an Akan verb, kyekyere, which means 'to tie'. Also, (11) illustrates the bilingual ability of the girl and her interlocutor, the woman. It reveals how interlocutors sometimes accommodate to the speaker's language choice. Following the girl's use of the Akan word, kyekyere, 'to tie', the woman shifted from the initial use of English to Akan. Interestingly, the girl shifted back to the use of English in her response.

\section{Bilingualism/multilingualism}

Bilingualism or multilingualism is another language practice that prevails in the households and the external environments. Bilingualism is a term which refers to the use of two languages of an individual (Wu, 2005). Multilingualism, on the other hand, may be defined as one's ability to speak more than two languages (Baquedano-López \& Kattan, 2007). The two terms can be used for an individual, to refer to the individual's competence in the use of two or more languages. When used to describe the society, bilingualism or multilingualism refers to the use of at least two languages in a given speech community. At home, school or play, 
Nutakor, Y. E. \& Amfo, N. A. A./ Language socialisation practices of children inside and outside the compound, the children take advantage of their engagement in both dominant and non-dominant languagemediated interactions to learn and acquire new language(s) hence their bilingual or multilingual abilities enable them to easily socialise and communicate meaningfully.

It is observed that the children get access to multiethnic interconnectivities where they are immersed in the use of multiple languages. Consequently, the children make effort to improve their English and learn dominant language(s) from one another and the socialising agents, as their repertoire encompasses more than two languages (Ghanaian and non-Ghanaian language combination) which they have the opportunity to use on daily basis. This characteristic is demonstrated in the children's language use patterns within the various communicative events - play, conversation, etc. For instance: Kofi, a boy in Nima, is multilingual in four languages, namely Kotokoli, Hausa, Akan and English. He uses any of these languages with his interlocutors, depending on their available linguistic codes and the topic under discussion.

Again, Maame $\mathrm{S}$, a native of Larteh, who is a bilingual (in Larteh and Akan), transmits her language and culture to her children by telling them stories in her ethnic language (L1), Larteh. On one of such occasions, when she was using Larteh to tell a story, she switched to the use of Akan at some point. To explain her action, Maame S said that she changed to Akan because two other children who had joined later did not understand Larteh. This case illustrates how adults within the communities are sensitive to children's linguistic competencies and adjust to these competencies. During the discussion, Akan was the main code used. The children actively participated in the communicative event by answering questions in Akan on lessons learnt from the story.

In Accra Newtown, a mother explicitly uses two languages (English and Akan) with her child. Example 12 illustrates how she uses the two languages. 
Nutakor, Y. E. \& Amfo, N. A. A./ Legon Journal of the Humanities 29.1 (2018)

12. Mother: Brother, greet madam. Say 'Good morning'.

Mother: ko kyea madam.

Go greet madam

'Greet madam.'

$\mathrm{Ka} \quad \mathrm{s} \varepsilon$

Say COMP good morning

'Greet good morning.'

This practice of individual bilingualism or multilingualism is a response to the children's ability to participate actively in activities of the home, compound houses, school, their environs and the larger communities to which the children are exposed daily.

In Nima, a speech community with shared values (cf. SavilleTroike, 2003), children use Hausa as a medium of communication in most situations, throughout playtime in the environs. A switch to Akan or English is preferable only when they realise the interlocutor cannot communicate with them in Hausa. It is evident that Hausa is a home language for majority of the children in Nima but not necessarily their ethnic language. It is used as the lingua franca for most immigrants from Northern Ghana who have settled in Nima. Thus, Hausa is the language commonly used by both adults and children in addressing each other, giving instructions, reporting, insulting, etc. hence its use encourages many children to actively participate in communicative events. In addition, we notice that though all children observed in Accra Newtown and Madina have the dominant languages, English or Akan, in their repertoire, these two languages were not actively used among the children in Nima.

\section{Language shift and/or maintenance.}

Batibo (2005) explains language maintenance and/or shift as a language contact situation in which a speech community may use their respective languages in all domains or prefer to learn and use a new language in all domains or use the newly acquired language in specified domains. Despite the fact that some parents motivate their children to learn their ethnic language(s) by using it/them as a medium of interaction at home with their children, the dominance 
Nutakor, Y. E. \& Amfo, N. A. A./ Language socialisation practices of children of Akan, English and Hausa in the communities greatly influences children's socialisation patterns. Some of the parents, thus rather socialise the children to these dominant languages - English, Akan and Hausa, at the expense of their own ethnic languages. For instance, an Akan couple in Nima uses Hausa with their child in all domains, but uses Akan with one another. Such practices appear to account for the mismatch in children's first language and their parents' ethnic language. Some parents with the language maintenance view buy story books and beginner's readers in their ethnic languages for their children. This effort gives the children an opportunity to have a shared repertoire with their parents at home and its environs.

\section{Attitudes regarding children's language learning and use}

The participants' language use pattern suggests a fluid correlation of socialising agents' language practice and attitudes. Twelve parents out of twenty (i.e. 60\%) have a positive attitude towards their children's individual bilingualism, especially their ability to use English in various domains. The expectation is that with those linguistic skills, the children would easily cope in various socio-economic settings. A parent in Accra Newtown had this to say:

\section{Accra Newtown parent (2:00 pm) 18/08/14}

When my child speaks English, I become so excited because it is the language which is used at many official functions. It is the official language of the country. I have actually invested in it so that in the near future my child could secure a white-collar job.

This assertion lends support to Dako \& Quarcoo's (2017) finding that, on account of its prestige, parents feel compelled to use English at home instead of their own native languages. This observation also corroborates Andoh-Kumi's (1997) finding that some parents get disappointed when they realise that their children learn their own native languages at school. 
It was evident that a few parents (5) felt anxious and tensed that their children's use of English would appear to give rise to lack of knowledge of their cultural values, which are embedded in their language(s). This group of parents set great store by the development of their cultural and social identity. It appears that if their children cannot speak their indigenous languages, it will become very difficult for them to integrate into their home environment (home village/town). This is what one parent had to say:

14. Nima parent (3:30 pm) $23 / 08 / 14$

I do not want my village folks to insult me for not doing the right thing. If I do not socialise my children with Asante-Twi and the children get to Kumasi, which language will they speak with my mother who cannot speak English or Ga? I feel those parents who socialise their children with English or another language rather than theirs are not proud of their first language, but my husband and I are proud of our language.

In this scenario, the lack of opportunity to speak the ethnic language of one's parents means lack of shared values as one may not be accepted as a member of the speech community, particularly in the home village/town.

Still fewer parents (only three out of twenty) are neutral as they are indifferent to their children's ability to speak more languages inclusive of their ethnic language. For this group, so long as the children can cope with the language contact situation at home and in the school, they are fine.

\section{Madina parent (1:30 pm) 24/08/14}

You know that no matter how well I speak English with my children, they may not be as good as the children who are native speakers. Their English will never be like the native English children because 
Nutakor, Y. E. \& Amfo, N. A. A./ Language socialisation practices of children they are Ghanaians who have their ethnic languages. For English, when they go to school, I am very sure that their teachers will teach them to make up for the skills they lack.

From the observations and discussions with the children, it is evident that the children's ability to actively participate in the various communicative events and situations is largely related to language choice patterns of parents and other socialising agents. As a result, children's language socialisation practices, language use patterns and ability to actively participate during communicative events depend largely on the positive and negative experiences that co-exist in the multilingual environments and how the socialising agents perceive the languages and people who use such codes.

In the case of lack of proficiency in English, Akan, Hausa, Ewe or Ga, some of the children who could not actively interact with their peers felt the need to learn one of these languages. Some of the older children contend that their use of English is a sign of prestige. Its use puts them in the privileged class within the communities. The various attitudes of the parents, neighbours and peers towards the language socialisation of children in this study confirms what Pease-Alvarez (2003) identified in her study of parental ideologies on children's Spanish language socialisation. She asserts that some parents abandon the use of Spanish and shift to the use of English with their children. She adds that these parents prioritise the need for work outside the speech community over identity development.

\section{Conclusion}

In this paper, we have discussed the prospects of children learning language(s) and developing bi/multilingual abilities in Ghana with a focus on compound houses in Accra, which are multiethnic and multicultural contexts suitable for these abilities. It is shown that the children's language experiences in the households are different from, and are sometimes overshadowed, by the language used in the macro environment. Majority of children in the compound houses of Accra New Town and Madina use 
English in all domains, while children in Nima use English largely in the school but not within their informal social networks. Three languages - English, Akan and Hausa, are the active and predominant languages used in all the informal communicative events within the compound houses in all the three suburbs, with Ewe and Ga having some restricted domains of use (in-group languages). In the compound houses, the children's language choices and use reflect, to some extent, their parents' shift from socialising the children to use a Ghanaian language as a first language to English. Again, some parents use dominant languages, such as Akan and Hausa, to the disadvantage of their ethnic language(s). However, few parents reinforced their ethnic language in their children's repertoire. Over time, and in response to one's ability to participate in most, if not all communicative events in the speech community, the children were motivated to learn multiple languages, where Akan and/or English is/are constant, while Hausa is peculiar to those who reside in Nima. To cope with the diversity of their play groups and topics for discussions, the children code-mix during interactions. The communicative contexts, events, as well as the socialising agents' language choices combine to play a crucial role in the development of bi/multilingual abilities of children. These abilities are not always reflective of the parents' ethnic languages. In this regard, we encourage an ethnographic study on how the language socialisation practices aid the children's literacy and numeracy development at school. 


\section{References}

Andoh-Kumi, K. (1997). Language education policies in Ghana. Accra: CRIGLE.

Ayoola, K. A., \& Soneye, T. O. (2016). Mother tongue eclipsing in the linguistic repertoire of Yoruba/English bilingual children in Nigeria. Legon Journal of the Humanities, 27(1), 95-118.

Baquedano-López, P., \& Kattan, S. (2007). Growing up in multilingual community: Insights from language socialisation. In P. Auer \& L. Wei (Eds.), Handbook of multilingualism and multilingual communication (Vol. 5, pp. 69-99). The Hague: Mouton de Gruyter.

Batibo, H. (2005). Language decline and death in Africa: Causes, consequences and challenges. Toronto: Multilingual Matters.

Bibiebome, E. Z. (2010). Language shift and language maintenance of $G a$ in Accra. (MPhil thesis). University of Ghana, Legon, Ghana.

Cook, H. M. (1999). Language socialisation in Japanese elementary schools: Attentive listening and reaction turns. Journal of Pragmatics, 31, 1443-1465.

Dako, K., \& Quarcoo, M. A. (2017). Attitudes towards English in Ghana. Legon Journal of the Humanities, 28(1), 20-30.

Delgado, M. R. (2009). Spanish heritage language practices of a family of Mexican origin (PhD dissertation). University of Arizona, Graduate College, Tucson, USA.

Duff, P. (2006). Problematising language socialisation across post-secondary contexts. A paper presented at the annual conference of the American Association for Applied Linguistics, Montreal, Canada. 17th -20th June, 2006.

Garrett, P., \& Baquedano-López, P. (2002). Language socialization:

Reproduction and continuity, transformation and change. Annual Review of Anthropology, 31, 339-361.

Ghana Statistical Service. (2012). 2010 Population and Housing Census Report. Accra: Sakoa Press Limited.

Ghimenton, A., Chevrot, J. P., \& Billiez, J. (2013). Language choice adjustments in child production during dyadic and multiparty interactions: A qualitative approach to multilingual interactions. Linguistics, 51(2), $381-411$.

Gleason, J. B., \& Ratner, N. (Eds.), (1998). Language acquisition. Psycholinguistics (pp. 347-407). Belmont, CA: Thomson Wadsworth

Gleason,J. B., \& Weintruaub, S. (1978). Input language and the acquisition of communicative competence. In K. Nelson (Ed.), Children's Language, (Vol.1, pp. 171-222). New York: Gardner Press. 
Guerini, F. (2007). Multilingualism and language attitudes in Ghana: A preliminary survey. A paper presented at the International Symposium on Bilingualism (ISB6), University of Hamburg, Germany. 29th May to 2nd of July, 2007.

Howard, K. (2003). Language socialisation in Northern Thai bilingual community. (PhD dissertation). University of California, Los Angeles, USA.

Huang, C. (2011). Language socialisation of affect in Mandarin parent-child conversation. Pragmatics, 21 (4), 593-618.

Hymes, D. (1962). The ethnography of speaking. In T. Gladwin \& W. C.

Sturtevant (Eds.), Anthropology and human behaviour (pp. 13-53).

Washington, DC: Anthropology Society of Washington.

Ildikó, E. (2010). The language socialisation of the children living in multilingual environment. (PhD dissertation). University of Szeged. Szeged, Hungary.

Luykx, A.(2003). Weaving languages together: Family language policy and gender socialisation in bilingual Aymara households. In R. Bayley \& S. R. Schecter (Eds.), Language and socialization in bilingual and multilingual societies (pp. 25-43). Clevedon, UK: Multilingual Matters.

Makihara, M. (2013). Language, competence, use, ideology, and community on Rapa Nui. Language and Communication, 33(4), 439-449. Elsevier. http://dx.doi.org/10.1016/j.langcom

Minks, A. (2010). Socialising heteroglossia among Miskitu children on the Caribbean Coast in Nicaragua. Pragmatics, 20(4), 495-522.

Morgan, M. H. (2014). Speech communities. Cambridge, UK: Cambridge University Press. http://doi.org/10.1017/CB09781139151269

Ochs, E. (1988). Culture and language development: Language acquisition and language socialisation in Samoan village. Cambridge, UK: Cambridge University Press.

Ochs, E., \& Schieffelin B. (1984). Language acquisition and socialisation: Three developmental stories and their implications. In R. A. Schweder \& R. A. LeVine (Eds.), Culture theory: Essays on mind, self, and emotion (pp. 276-320). New York: Cambridge University Press.

Park, S. M., \& Sarkar. M. (2007). Parents' attitudes toward heritage language maintenance for their children and their efforts to help their children maintain the heritage language: A case study of Korean-Canadian immigrants. Language, Culture and Curriculum, 20(3), 223-235, doi: $10.2167 / \operatorname{lcc} 337.0$ 
Nutakor, Y. E. \& Amfo, N. A. A./ Language socialisation practices of children

Pease-Alvarez, L. (2003). Transforming perspectives on bilingual language socialization. In R. Bayley \& S. R. Schecter (Eds.), Language and socialisation in bilingual and multilingual societies (pp. 9 -24). Clevedon, UK: Multilingual Matters

Saville-Troike, M. (2003). The ethnography of communication. Oxford: Blackwell.

Schieffelin, B., \& Ochs, E. (1986a). Language socialisation. Annual Review of Anthropology, 15, 163-191.

Schieffelin, B., \& Ochs, E. (1986b). Language socialisation across cultures. Cambridge, UK: Cambridge University Press

Tsikpo, T. K. (2010). Linguistic behaviour of children of Ewe origin in Accra. (MPhil thesis). University of Ghana, Legon, Ghana.

Wenger, E. (1998). Communities of practice: Learning, meaning and identity. Cambridge, UK: Cambridge University Press.

Wolff, E. (2000). Pre-school child multilingualism and its educational implications in the African context. Cambridge, UK: Cambridge University Press.

Wu, C. (2005). Attitude and behavior toward bilingualism for Chinese parents and children. In J. Cohen, K. T. McAlister, K. Rolstad \& J. MacSwan (Eds.), Proceedings of the 4th International Symposium on Bilingualism (pp. 2385-2394). Somerville, MA: Cascadilla Press. 